\title{
Effect of Agricultural Countermeasures on Ingestion Dose Following a Nuclear Accident
}

\author{
Dong-Kwon Keum ${ }^{1, *}$, Hyojoon Jeong' ${ }^{1}$ In Jun', Kwang-Muk Lim', Yong-Ho Choi', So-Hyeon Lee², Tae-Jong Jung² \\ ${ }^{1}$ Korea Atomic Energy Research Institute, Daejeon, Korea; ${ }^{2}$ University of Science and Technology, Daejeon, Korea
}

\section{Original Research}

Received November 1, 2018

Revision December 5, 2018

Accepted January 3, 2019

Corresponding author:

Dong-Kwon Keum

Korea Atomic Energy Research Institute, 989-111 Daedeok-daero, Yuseong-gu,

Daejeon 34057, Korea

Tel: $+82-42-868-2058$

Fax: +82-42-868-8606

E-mail: dkkeum@kaeri.re.kr

This is an Open-Access article distributed under the terms of the Creative Commons Attribution NonCommercial License (http://creativecommons.org/ licenses/by-nc/4.0) which permits unrestricted noncommercial use, distribution, and reproduction in any medium, provided the original work is properly cited.

Copyright $\odot$ 2019The Korean Association for Radiation Protection

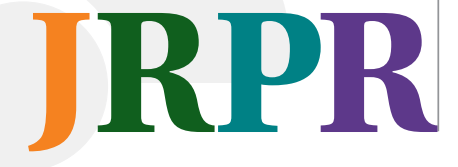

Background: Management of an agricultural food product system following a nuclear accident is indispensable for reducing radiation exposure due to ingestion of contaminated food. The present study analyzes the effect of agricultural countermeasures on ingestion dose following a nuclear accident.

Materials and Methods: Agricultural countermeasures suitable for domestic farming environments were selected by referring to the countermeasures applied after the Fukushima accident in Japan. The avertable ingestion doses that could be obtained by implementing the selected countermeasures were calculated using the Korean Agricultural Countermeasure Analysis Program (K-ACAP) to investigate the efficiency of each countermeasure.

Results and Discussion: Of the selected countermeasures, the management of crops was effective when radionuclide deposition occurred during the growing season of plants. Treatment by soil additive and topsoil removal was effective when deposition occurred during the nongrowing season of plants. The disposal of milk was not effective owing to the small contribution of milk to the overall ingestion dose. Clean feeding of livestock was effective when deposition occurred during the growing season of fodder plants such as pasture and rice-straw. Finally, the effect of food restriction increased with the soil deposition density of radionuclide. The practical effect of countermeasures was very small when the avertable ingestion dose was absolutely low.

Conclusion: The agricultural countermeasures selected to reduce the radionuclide ingestion dose after a nuclear accident must be made appropriate by considering the accident situation, such as the soil deposition density of the radionuclide and the deposition date in relation to farming cycles.

Keywords: Nuclear accident, Agricultural countermeasures, Avertable ingestion dose, K-ACAP

\section{Introduction}

The large-scale nuclear accidents such as those at Chernobyl and Fukushima bring about the release of large amounts of radioactive materials into the environment. The released materials are long lasting in the environment and have harmful effects on people and wild ecosystems through various exposure pathways.

The response to a nuclear emergency varies with the time that has passed since the accident. For the early phase of an accident, rapid public protection actions such as evacuation and sheltering are implemented. From the moment when the environmental release of radioactive materials no longer occurs, actions for post-accident recovery such as the decontamination of residential areas and agricultural land begin so that 
people may return to their normal life and economic activities as soon as possible. After the Chernobyl accident in 1986, there was a particular focus on remediation measures for animal products [1]. Radical improvement of agricultural land by such as plowing, reseeding, and fertilizing was extensively implemented in the first five years $[2,3]$. The properties attributable to these agricultural countermeasures are described in detail in a handbook [4]. In addition, a decision support system to estimate the radiological consequences of contamination of agricultural production, along with the effectiveness and costs of countermeasure strategies, were also developed [5]. Moreover, after the Fukushima accident in 2011, studies on the decontamination of agricultural land and the safety of agricultural products have been carried out extensively in Japan [6-9]. In particular, various decontamination countermeasures such as topsoil removal and potassium fertilizer application have been focused upon as steps to reduce the activity concentration of rice, which a staple crop in Japan [10-12]. The management of the agricultural food product system is very important for reducing radiation exposure by ingestion of contaminated food after a nuclear accident.

At present, a Korean decision support system is being developed to manage a contaminated agricultural food system after a nuclear accident. This requires information on the effectiveness of indispensable agricultural countermeasures. The purpose of the present study was to analyze the effectiveness of agricultural countermeasures through estimation of the ingestion dose that could be avoided by implementing each countermeasure following a nuclear accident.

\section{Materials and Methods}

\section{Agricultural countermeasures}

Many agricultural countermeasures would be needed to manage an agricultural food system following a nuclear accident, and many have been derived from the European agricultural responses after the Chernobyl accident [2-4]. In this study, agricultural countermeasures were selected by referring to the agricultural countermeasures applied after the Fukushima accident in Japan, which has farming characteristics similar to those in Korea. Table 1 shows the selected agricultural countermeasures and calculation conditions used for each countermeasure.

The efficiency of agricultural countermeasures on ingestion dose varies depending on various factors such as the soil
Table 1. Selected Countermeasures and Calculation Conditions

\begin{tabular}{|c|c|c|}
\hline Code & Countermeasures & Calculation conditions \\
\hline $\mathrm{CO}$ & No action & Reference case \\
\hline $\mathrm{C} 1$ & $\begin{array}{l}\text { Disposal of all plants } \\
\text { in accident year }\end{array}$ & $\begin{array}{l}\text { Set the activity concentration of all } \\
\text { plants to zero value until the next } \\
\text { harvest }\end{array}$ \\
\hline $\mathrm{C} 2$ & $\begin{array}{l}\text { Disposal of growing } \\
\text { plants at the time of } \\
\text { accident }\end{array}$ & $\begin{array}{l}\text { Set the activity concentration of } \\
\text { growing plants at the deposition time } \\
\text { to zero value until the next harvest }\end{array}$ \\
\hline C3/C31 & $\begin{array}{l}\text { Application of soil } \\
\text { additive }\end{array}$ & $\begin{array}{l}\text { Set the soil-plant transfer factor to } 0.2 \\
\text { (C3) or } 0.9 \text { (C31) of reference value }\end{array}$ \\
\hline $\mathrm{C} 4 / \mathrm{C} 41$ & $\begin{array}{l}\text { Removal of surface } \\
\text { soil }\end{array}$ & $\begin{array}{l}\text { Assumption of } 80 \%(C 4) \text { or } 20 \%(C 41) \\
\text { removal of radioactivity in surface soil }\end{array}$ \\
\hline C5 & $\begin{array}{l}\text { Ban of milk ingestion } \\
\text { for one year }\end{array}$ & $\begin{array}{l}\text { Set the activity concentration of milk to } \\
\text { zero value for one year after accident }\end{array}$ \\
\hline C6 & $\begin{array}{l}\text { Clean feeding of } \\
\text { livestock }\end{array}$ & $\begin{array}{l}\text { Set the activity concentration of all } \\
\text { fodder plants to zero value for one } \\
\text { year after accident }\end{array}$ \\
\hline $\mathrm{C} 7$ & $\begin{array}{l}\text { Restriction of food } \\
\text { exceeding standard }\end{array}$ & $\begin{array}{l}\text { Set the ingestion activity concentration } \\
\text { of foodstuffs exceeding standard } \\
\text { (100 Bq/kg for radioactive cesium) to } \\
\text { zero value }\end{array}$ \\
\hline C8 & $\begin{array}{l}\text { Enhance of } \\
\text { intervention level of } \\
\text { C7 }\end{array}$ & $\begin{array}{l}\text { Set the ingestion activity concentration } \\
\text { of foodstuffs exceeding half of } \\
\text { standard ( } 50 \mathrm{~Bq} / \mathrm{kg} \text { for radioactive } \\
\text { cesium) to zero value }\end{array}$ \\
\hline
\end{tabular}

deposition density, accident date, and the growth stage of crops at the time of deposition. In this study, the efficiency (E) is defined as the ratio of the 10-year accumulated ingestion dose of an adult exposed without any countermeasures, against the 10-year accumulated ingestion dose of an adult who could avoid some exposure due to the countermeasures implemented.

$\mathrm{E}=\frac{10-\text { year avertable ingestion dose }}{10-\text { year ingestion dose without countermeasure }} \times 100 \%$

Efficiency of $100 \%$ for a countermeasure indicates that an adult could avoid all ingestion doses by implementing the countermeasure. The efficiency and avertable ingestion dose for the selected countermeasures were calculated using the Korean Agricultural Countermeasure Analysis Program (KACAP) [13], which was designed to estimate the effects of agricultural countermeasures. The K-ACAP makes use of the Korean food chain model to calculate the ingestion dose after a nuclear accident $[14,15]$.

\section{Scenario}

Radioactive cesium $\left({ }^{137} \mathrm{Cs}\right.$ and $\left.{ }^{134} \mathrm{Cs}\right)$ was assumed to be deposited on the ground with a deposition density in the range $1 \times 10^{4}$ to $3 \times 10^{6} \mathrm{~Bq} \cdot \mathrm{m}^{-2}$ by referring to a result of the Fukushima accident [16]. Twelve different deposition dates 

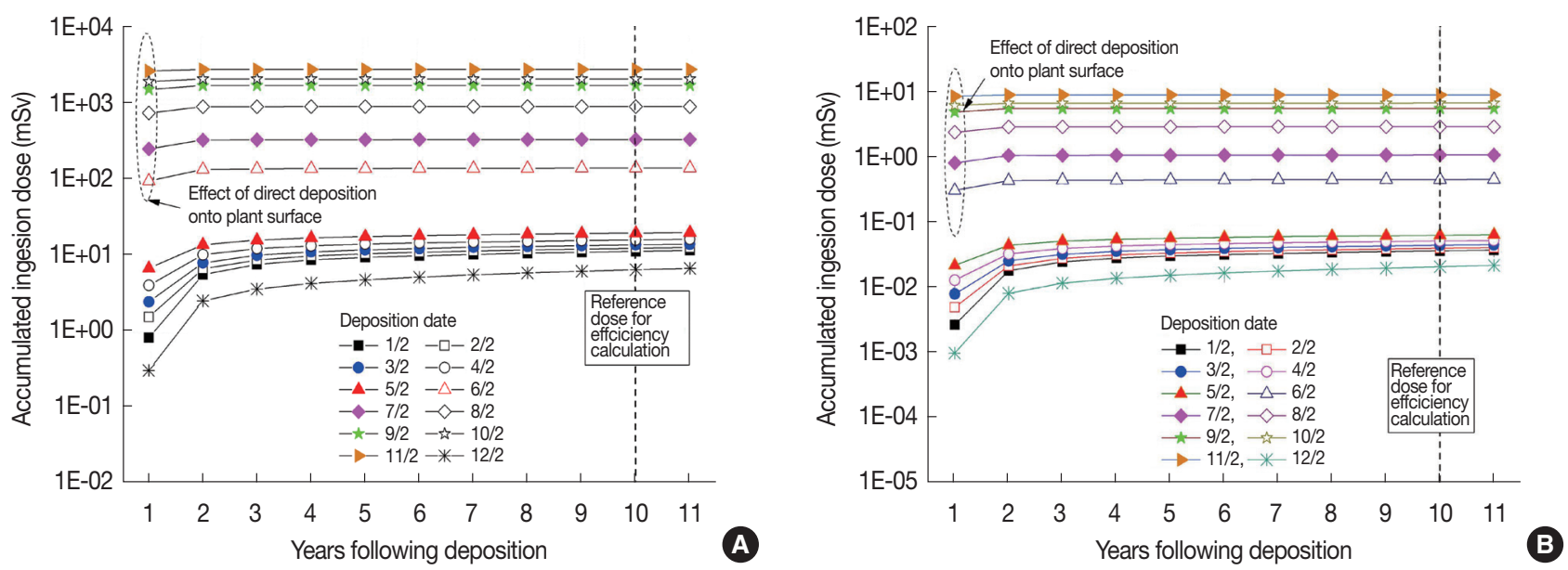

Fig. 1. Accumulated ingestion dose for the case of no-action (A) deposition density: $3 \times 10^{6} \mathrm{~Bq} \cdot \mathrm{m}^{-2}$ and $(\mathrm{B})$ deposition density: $1 \times 10^{4} \mathrm{~Bq} \cdot \mathrm{m}^{-2}$.

were investigated to show the effect of deposition date on the agricultural countermeasures. The growth stage of plants for each deposition date was taken from the K-PUBDOSE [14].

\section{Results and Discussion}

\section{Reference case (C0)}

Figure 1 shows the accumulated ingestion dose of an adult for two different deposition densities when countermeasures are not implemented. For the case of deposition during the growing season of plants (the deposition cases of June 2 to November 2), most of the ingestion dose occurred during the first year after the accident. This result was attributed to the high activity concentration of plants arising from direct deposition on the plant surfaces. On the other hand, when deposition occurred during the non-growing season of plants, plants were contaminated through the pathways of root-uptake following percolation into the root zone soil. In general, the activity concentration of plants is low when there is no direct deposition. Irrespective of the deposition density, most of the ingestion dose occurs within a few years after deposition. This indicates that the management of food within the first few years after an accident becomes a very effective action for public protection by reducing the longterm exposure dose.

Because the ingestion dose varies with time, the 10-year accumulated ingestion dose was used as the reference dose for each deposition date and soil deposition density. The calculated reference doses are summarized in Table 2. These values are used as the denominator to calculate the efficiency of each countermeasure.
Table 2. Reference Dose for Calculating Efficiency of Countermeasures (mSv)

\begin{tabular}{ccc}
\hline \multirow{2}{*}{ Deposition date } & \multicolumn{2}{c}{ Soil deposition density } \\
\cline { 2 - 3 } & $3 \times 10^{6} \mathrm{~Bq} \cdot \mathrm{m}^{-2}$ & $1 \times 10^{4} \mathrm{~Bq} \cdot \mathrm{m}^{-2}$ \\
\hline $1 / 2$ & 11.10 & 0.04 \\
$2 / 2$ & 12.16 & 0.04 \\
$3 / 2$ & 13.48 & 0.04 \\
$4 / 2$ & 15.66 & 0.05 \\
$5 / 2$ & 19.22 & 0.06 \\
$6 / 2$ & 136.41 & 0.45 \\
$7 / 2$ & 322.94 & 1.08 \\
$8 / 2$ & 872.73 & 2.91 \\
$9 / 2$ & $1,649.60$ & 5.50 \\
$10 / 2$ & $2,003.50$ & 6.68 \\
$11 / 2$ & $2,670.20$ & 8.90 \\
$12 / 2$ & 6.37 & 0.02 \\
\hline
\end{tabular}

Figure 2 shows the effect of foodstuffs on the accumulated ingestion dose for the reference case. The contribution of foodstuffs on the ingestion dose is different depending on the deposition date. When the deposition occurred on April 2 , in the non-growing season of plants (Figure 2A), the contribution of foodstuffs appeared in the order of vegetables, fruit, rice, beef, milk, pork, chicken, and eggs. When the deposition happened on November 2, in the growing season of vegetables (Figure 2B), the influence of vegetables on the ingestion dose was dominant owing to its high activity concentration by direct deposition. All other plants except for vegetables had been already been harvested by the time of deposition; therefore, they started being contaminated by root uptake after the next year of planting, and new plant production had low activity concentration. In the case of November deposition, the contribution of foodstuffs to the ingestion 

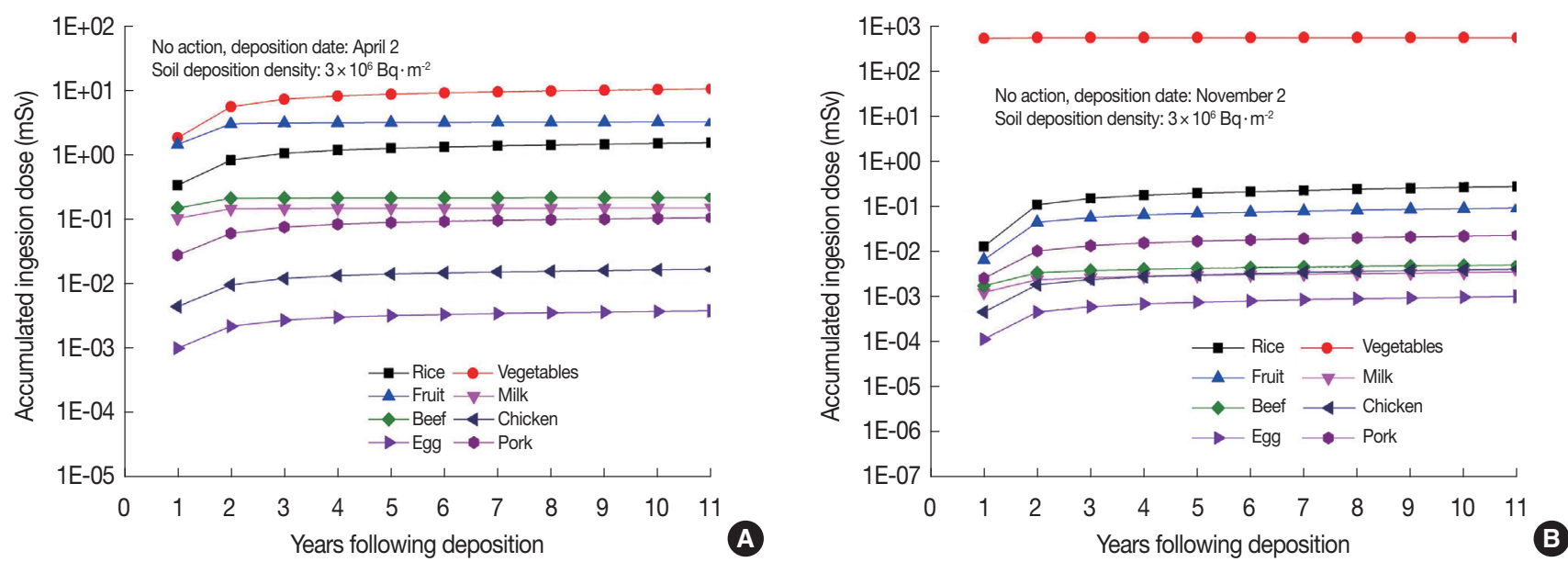

Fig. 2. Effect of foodstuffs on accumulated ingestion dose (A) deposition date: April 2 and (B) deposition date: November 2.
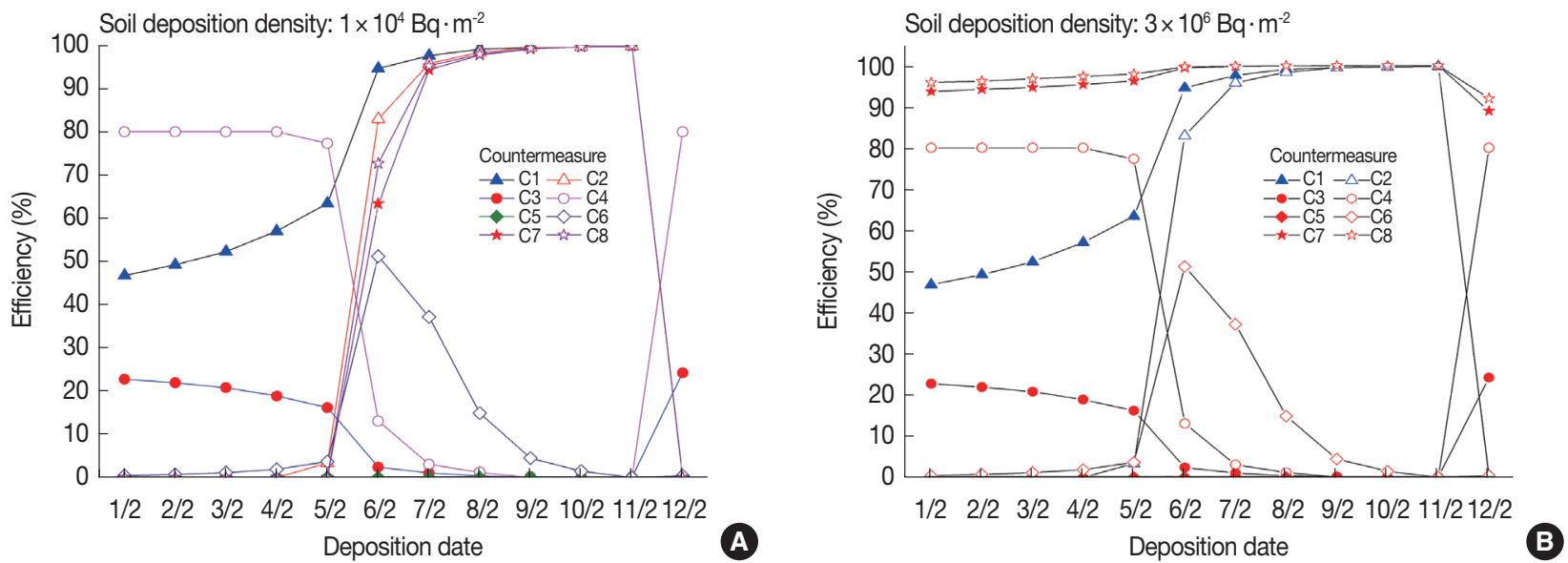

Fig. 3. Efficiency of countermeasures according to deposition date $(\mathrm{A})$ deposition density: $1 \times 10^{4} \mathrm{~Bq} \cdot \mathrm{m}^{-2}$ and (B) deposition density: $3 \times 10^{6}$ $\mathrm{Bq} \cdot \mathrm{m}^{-2}$.

dose appeared in the order of vegetables, rice, fruit, pork, beef, milk, chicken, and eggs.

\section{Effectiveness of countermeasures $\mathrm{Cl}$ to $\mathrm{C} 8$ \\ 1) Efficiency and avertable dose}

Figures 3 and 4 show the efficiency and avertable doses for countermeasures $\mathrm{C} 1$ to $\mathrm{C} 8$, respectively. Countermeasures $\mathrm{C} 1$ and C2 (disposal of plants) appeared to be very effective if deposition occurred during the growing season of crops. These countermeasures dispose of the crops with high activity concentration arising from direct deposition, and consequently, they can reduce much of the ingestion dose. Countermeasure C3 (application of soil additive) appeared to be effective in the case of deposition during the non-growing season of plants. The application of fertilizer to the soil leads to the reduction of the root uptake of radioactive cesium through competitive absorption of the potassium and calcium in fertilizers, rather than the cesium. For the case of deposition during the growing season of plants, Countermeasure C3 appeared not to be effective because the effect of direct deposition was much greater than that of root uptake. Countermeasure C4 (topsoil removal) cannot be carried out during the growing season of crops; thus, the effect of $\mathrm{C} 4 \mathrm{ap}$ peared to increase when the number of plants growing at the time of deposition was small. For the case of the deposition during the non-growing season of plants, the efficiency of $\mathrm{C} 4$ was proportional to the removal fraction of surface soil radioactivity. Countermeasure C5 (disposal of milk) was not effective irrespective of deposition date because the contribution of milk to the total ingestion dose was very low. Countermeasure C6 (clean feeding of livestock for one year after an accident) was effective when the activity concentration of 

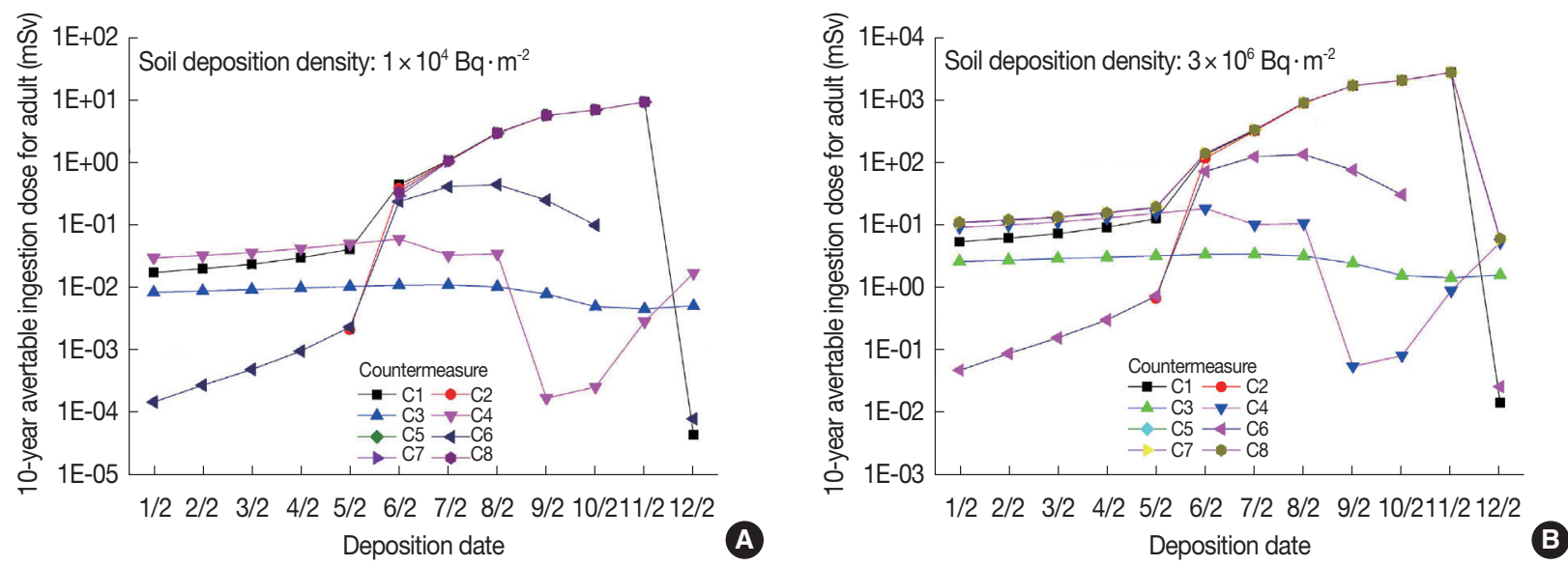

Fig. 4. Avertable ingestion dose according to deposition date (A) deposition density: $1 \times 10^{4} \mathrm{~Bq} \cdot \mathrm{m}^{-2}$ and (B) deposition density: $3 \times 10^{6} \mathrm{~Bq} \cdot \mathrm{m}^{-2}$.

the original fodder (grasses, rice-straw, and corn) was higher; therefore, Countermeasure C6 appeared to be effective when deposition occurred in the growing season of the fodder plants.

On the other hand, the efficiencies of countermeasures $\mathrm{Cl}$ to $\mathrm{C} 6$ were not affected by the soil deposition density because the estimated ingestion dose for the countermeasures is proportional to the soil deposition density, as shown in Figure 3. Even though the efficiency of a countermeasure is high, the effectiveness of the countermeasure can be very low if the dose that is avertable is absolutely small (i.e., there is not much to ingest). For example, as shown in Figure 4A, when the soil deposition density is low, the activity concentration of the crops is absolutely low; therefore, the avertable dose for 10 years is not more than $8 \mathrm{mSv}$. Thus, the practical effect of such countermeasures would be very low. In this case, the cost for implementing the countermeasures is much higher than the public health benefit that could be obtained from avoidance of such doses. These conditions might not satisfy the justification criteria (benefit $>$ cost), which is one of the three principles of radiation protection. On the other hand, if the deposition density is high, as shown in Figure 4B, the ingestion dose to be avoided could be up to 2,670 mSv. High soil deposition density leads to high activity concentration of foodstuffs. Therefore, Countermeasures C7 and C8 (restriction of food intake) could be most effective for reducing the ingestion dose irrespective of deposition date.

2) Effect of deposition density on countermeasures C7 and C8

Figure 5 shows the effect of the soil deposition density on the efficiency of countermeasures C7 and C8. The efficiency

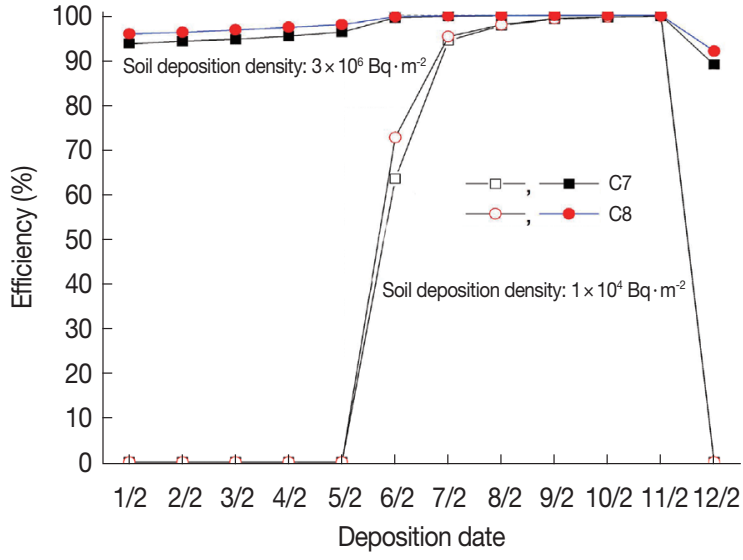

Fig. 5. Effect of soil deposition density on the efficiency of Countermeasure $\mathrm{C} 7$ and $\mathrm{C} 8$.

is affected greatly by the soil deposition density because the number of plants exceeding the intake standard of food increases with the deposition density. As the soil deposition density increases, more agricultural products that exceed the intake standard for food ( $100 \mathrm{Bg} \cdot \mathrm{kg}^{-1}$ for radioactive cesium) are produced irrespective of the deposition date. Therefore, even though deposition occurs during the non-growing season of plants, if the amount of radioactivity released is large, most of the ingestion dose can be avoided by implementing Countermeasures C7 and C8. However, in the case of low soil deposition density, the agricultural products exceeding the intake standard of food will be very small. Consequently, the restriction of food intake will not lead to the practical reduction of the ingestion dose. In this case, there is no practical difference in the ingestion (avertable dose) between the case of no action ( $\mathrm{C} 0$ ) and the countermeasures of food restriction (C7 and C8). 


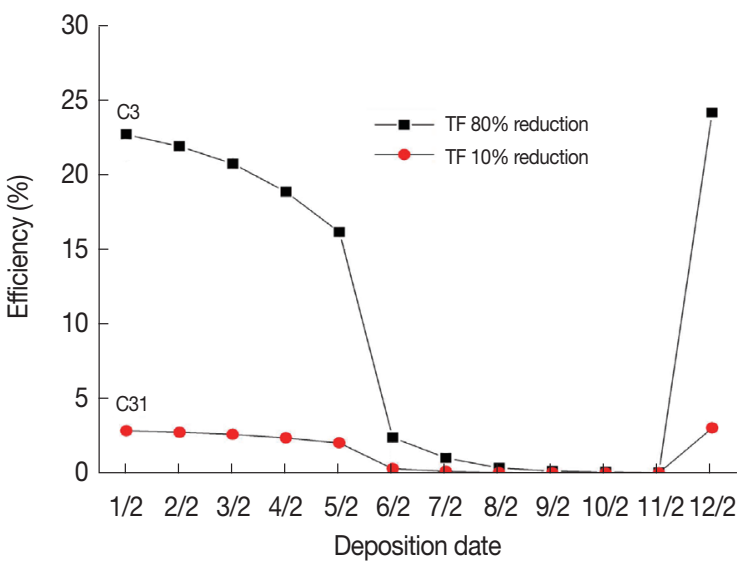

Fig. 6. Effect of soil-plant transfer factor (TF) on the efficiency of Countermeasure C3.

3) Effect of soil-plant transfer factor on Countermeasure C3

The purpose of Countermeasure $\mathrm{C} 3$ is to reduce the root absorption of radionuclides by the application of soil additives such as lime or potassium fertilizer. The application of soil additives reduces the root uptake rate of radionuclides by plants and consequently leads to a low value of the soilplant transfer factor (TF). Figure 6 shows the effect of TF on the efficiency of Countermeasure $\mathrm{C} 3$ when the $\mathrm{TF}$ is reduced to $80 \%$ (C3) and $10 \%$ (C31) of the reference value, respectively. The highest efficiency, $24 \%$ and $3 \%$ for C3 and C31, respectively, was obtained when the deposition occurred after the harvest of all crops (the case of the deposition date: December 2). The ratio of the reduction of dose against that of the TF values was about 0.3 at the maximum, indicating that indirect measures, such as the application of soil additive, are likely to be less effective compared to countermeasures that remove radioactivity directly from the food production system, such as surface soil removal.

\section{4) Effect of removal of radioactivity in surface soil on \\ Countermeasure $\mathrm{C} 4$}

The effect of the removal of radioactivity in surface soil on Countermeasure C4 (surface soil removal) is shown in Figure 7 . The higher removal of radioactivity in the surface soil results in less contamination of the root zone soil, and subsequently less activity concentration of plants. When root-uptake is the dominant pathway to contaminate plants, which is the case of deposition during the non-growing season, the decrease in activity concentration of plants is proportional to the removal fraction of radioactivity in surface soil.

On the other hand, in the present study, it was assumed

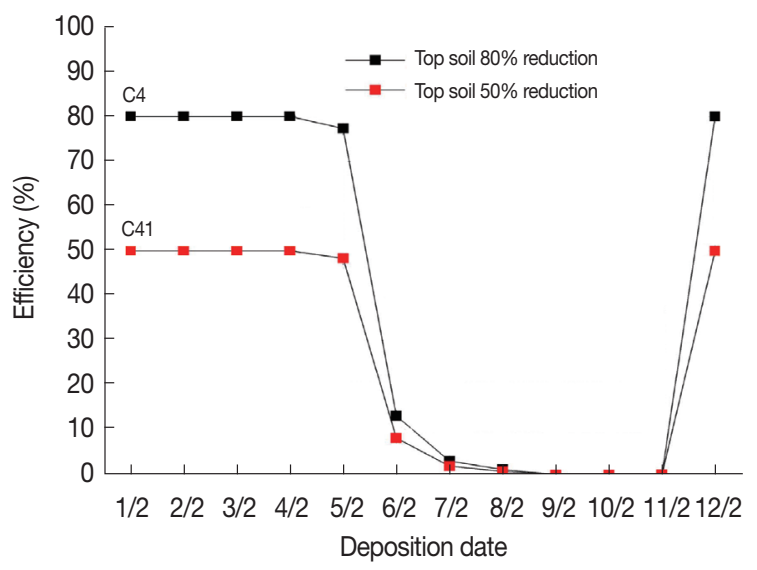

Fig. 7. Effect of the removal of radioactivity in surface soil on the efficiency of Countermeasure C4.

that the surface soil was not removed during the growing period of crops. This assumption led to low efficiency of Countermeasure $\mathrm{C} 4$ when deposition occurred during the growing season of plants (the cases of deposition during June 2November 2). For the case of deposition during the growing season, the radioactivity of the surface soil is reduced by the mixing effect of soil owing to plowing and also to the transport of radioactive substances into the root zone soil (percolation process). Consequently, the efficiency of $\mathrm{C} 4$ was relatively lower in the case of deposition during the growing season than for deposition during the non-growing season.

\section{Conclusions}

The effectiveness of agricultural countermeasures was analyzed through estimation of the avertable ingestion dose for each countermeasure. As the result of the analysis results, the management of crops was effective when deposition occurred during the growing season of plants, and the management of soil such as the treatment of soil additive and the topsoil removal was effective when deposition occurred during the non-growth season of plants. The disposal of milk was not effective owing to the small contribution made by milk to the ingestion dose, and clean feeding of livestock was effective when deposition occurred during the growth season of fodder plants such as pasture and rice-straw. The effect of food restriction increased with the soil deposition density of radionuclide. Irrespective of soil deposition density and deposition date, the practical effect of countermeasures was very small when the ingestion dose that could be averted was absolutely low. 
In conclusion, agricultural countermeasures to reduce the dose of radionuclide ingestion after a nuclear accident can be effective when they are selected appropriately by considering the specific accident conditions, such as soil deposition density of the radionuclide and the deposition date. In the future, this study will be extended to investigate the combined effect when multiple countermeasures are applied in parallel or in series.

\section{Acknowledgments}

This work was supported by a National Research Foundation of Korea (NRF) grant funded by the Korean government (NRF-2017M2A8A4015252).

\section{References}

1. Howard BJ, Fesenko S, Balanov M, Pröhl G, Nakayama S. A comparison of remediation after the Chernobyl and Fukushima Daiichi accidents. Radiat. Prot. Dosim. 2017;173(1-3):170-176.

2. Segal MG. Agricultural countermeasures following deposition of radioactivity after a nuclear accident. Sci. Total. Environ. 1993; 137:31-48.

3. Fesenko SV, Alexakhin RM, Balonov MI, Bogdevitch IM, Howard BJ, Kashparov VA, Sanzharova NI, Panov AV, Voigt G, Zhuchenka YM. An extended critical review of twenty years of countermeasures used in agriculture after the Chernobyl accident. Sci. Total. Environ. 2007;383:1-24.

4. European approach to nuclear and radiological emergency management and rehabilitation strategies. Generic handbook for assessing in the management of contaminated food production systems in Europe following a radiological emergency, EURANOS(CAT1)-TN(09)-01, 2009;1-407.

5. Jacobsen LH, Andersson KG, Charnock T, Kaiser JC, Gering F, Hoe SC, Larsen LJ. Implementation in ARGOS of ERMIN and AGRICP. Radioprotection. 2010;45(5):S191-S198.

6. International Atomic Energy Agency. The Fukushima Daiichi accident. Technical Volume 5/5 Post-accident recovery. 2015; $1-56$.
7. Nakano M, Yong RN. Overview of rehabilitation schemes for farmlands contaminated with radioactive cesium released from Fukushima power plant. Eng. Geol. 2013;155:87-93.

8. Japan Atomic Energy Agency. Use of knowledge and experience gained from the Fukushima Daiichi nuclear power station accident to establish the technical basis for strategic off-site response. JAEA-review 2015-001. 2015;44-57.

9. Nakanishi TM, Tanoi K. (editors) Agricultural implications of the Fukushima nuclear accident, Graduate school of agricultural and life sciences. First Ed. Tokyo, Springer Open, 2013;120-131.

10. Yang B, Onda Y, Ohmori Y, Sekimoto H, Fujiwara T, Wakiyama Y, Yoshimura K, Takahashi J, Sun X. Effect of topsoil removal and selective countermeasures on radiocesium accumulation in rice plants in Fukushima paddy field. Sci. Total. Environ. 2017;603604:49-56.

11. Kato N, Kihou N, Fujimura S, Ikeda M, Miyazaki N, Saito Y, Eguchi T, Itoh S. Potassium fertilizer and other materials as countermeasures to reduce radiocesium levels in rice: results of urgent experiments in 2011 responding to the Fukushima Daiichi Nuclear Power Plant accident. Soil. Sci. Plant. Nutr. 2015;.61(2):179190.

12. Yang B, Onda Y, Wakiyama Y, Yoshimura K, Sekimoto H, Ha Y. Temporal changes of radiocesium in irrigated paddy fields and its accumulation in rice plants in Fukushima. Environ. Pollut. 2015;208:562-570.

13. Korea Atomic Energy Research Institute. Attributable properties for agricultural countermeasures after nuclear accident and analysis of countermeasures effects, KAERI/TR-7320/2018.2018; 37-52.

14. Korea Atomic Energy Research Institute. Model (K-PUBDOSE) to evaluate the ingestion dose following a nuclear accident. KAERI/TR-7181/2018. 2018;47-70.

15. Keum DK, Jeong HJ, Jun I, Lim KM, Choi YH. Assessing the activity concentration of agricultural products and the public ingestion dose as results of a nuclear accident. J. Radiat. Prot. Res. 2018;43(2):39-49.

16. United nations Scientific Committee on the Effects of Atomic Radiation, Report to the general assembly, scientific annex A: levels and effects of radiation exposure due to the nuclear accident after the 2011 great East-Japan earthquake and tsunami. UNSCEAR 2013 Report Volume I. 2014;36-38. 